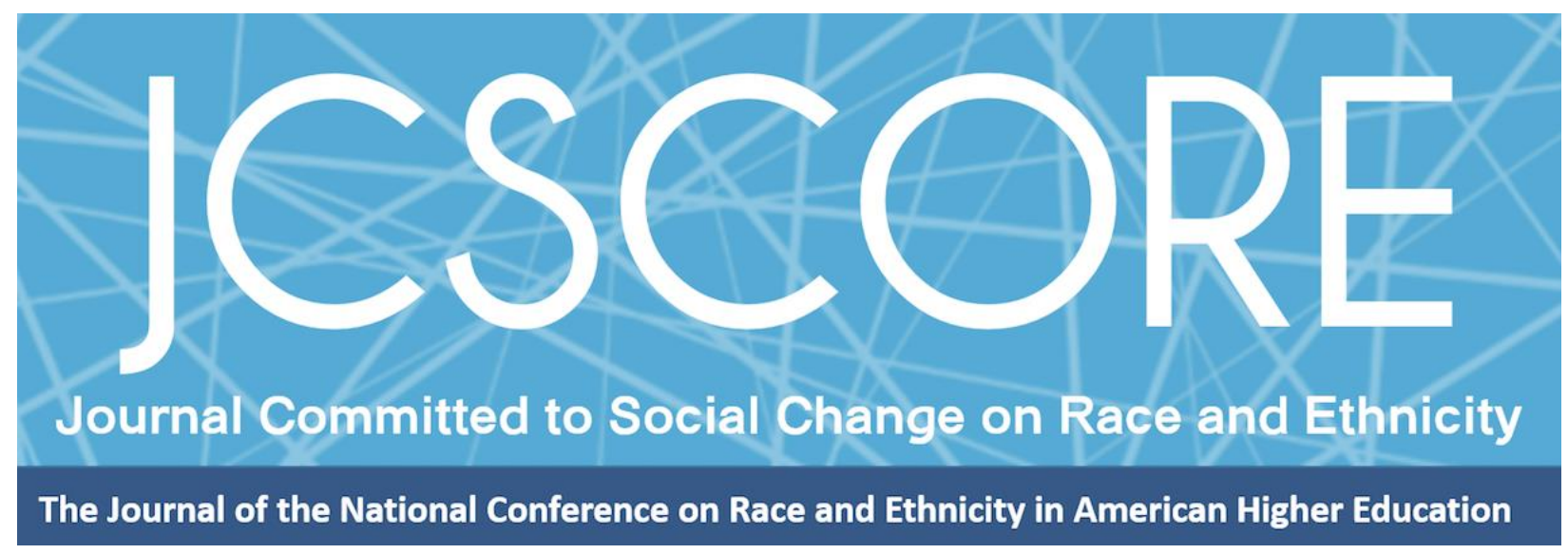

\title{
CAN HOLLAND'S PERSON-ENVIRONMENT FIT THEORY PRODUCE TROUBLING OUTCOMES FOR RACIAL/ETHNIC UNDERREPRESENTED STUDENTS IN STEM? AN ANALYSIS OF SOCIAL AGENCY
}

Juan Carlos Garibay

University of Virginia

Journal Committed to Social Change on Race and Ethnicity Volume 6, Issue 2 | 2020

This work is licensed under a Creative Commons Attribution-NonCommercial-ShareAlike 4.0 International License. Permission of the authors is required for distribution and for all derivative works, including compilations and translations. Quoting small sections of text is allowed as long as there is appropriate attribution and the article is used for non-commercial purposes.

The Journal Committed to Social Change on Race and Ethnicity (ISSN 2642-2387) is published by the National Conference on Race and Ethnicity (NCORE), a production of the University of Oklahoma, in partnership with the University of Oklahoma Libraries. 


\title{
Can Holland's Person-Environment Fit Theory Produce Troubling Outcomes for Racial/Ethnic Underrepresented Students in STEM? An Analysis of Social Agency
}

Juan Carlos Garibay

University of Virginia

\begin{abstract}
Increasing the success of Underrepresented Students of Color (USC) in science, technology, engineering, and mathematics (STEM) is a central concern to many researchers, policymakers, and educators. To help understand STEM college student success, many studies have utilized Holland's (1966, 1973, 1985, 1997) person-environment fit framework applying it uncritically to all students. Using Quantitative Criticalism, this study engages the racial realities of USC while investigating several assumptions of Holland's theory and their implications for USC pursuing STEM fields. Utilizing a national, longitudinal dataset of 5,564 STEM bachelor's degree recipients drawn from the Cooperative Institutional Research Program's 2004 Freshman Survey and 2011 Post-Baccalaureate Survey, this study specifically examines students' interest in making a positive impact on society through socio-political action, or social agency, which Holland's typology suggests is incongruent with STEM environments. Findings show that USC may be more likely to be described as "incongruent" with Holland's classification of STEM environments, that the congruence assumption may not be fully applicable for understanding the long-term success of USC in STEM, and that the social agency of USC did not significantly change over the seven years while white students' significantly decreased. Implications for broadening participation and promoting equity in STEM fields are discussed.
\end{abstract}

Considerable attention in higher education research has been given to understanding the factors that promote students' pursuit of and success in science, technology, engineering, and mathematics (STEM) disciplines. Of major concern is the significant disparity in completion rates between Underrepresented Students of Color ${ }^{1}$

\footnotetext{
'In this study, I use the National Science Foundation's (2019) categorization of 'underrepresented' in STEM to include American Indian/Alaska Native, Black/African American, and Latina/o students.

Author's Note: I would like to acknowledge and thank the anonymous reviewers for their critical insights, Dr. Brian Pusser and Dr. Leticia Oseguera for their thoughtful feedback on earlier versions of this manuscript, and Dr. Sylvia Hurtado for allowing the use of data from her project.
} 
Journal Committed to Social Change on Race and Ethnicity | Volume 6, Issue 2 | 2020

(USC; American Indian/Alaska Native, African American, and Latina/o students) and their non-USC peers pursuing STEM degrees (Higher Education Research Institute [HERI], 2010). In fact, a report by the National Science Foundation [NSF] indicates that since the year 2000, underrepresented students' participation in mathematics has dropped and share of engineering and physical science bachelor's degrees has been flat (NSF, National Center for Science and Engineering Statistics [NCSES], 2013).

While numerous theoretical and conceptual frameworks have been used to understand and explain the factors that affect students' access to and success in STEM fields, one prominent framework that has been used in higher education is Holland's $(1966,1973,1985,1997)$ career typology theory of vocational behavior, also known as person-environment (P-E) fit. Holland's $(1966,1973,1985,1997)$ career typology theory of vocational behavior has several tenets. First, Holland's theory indicates that student personalities and academic environments can be categorized into one of six types (e.g., realistic, investigative, artistic, social, enterprising, and conventional). Second, students seek out and select academic environments that match their distinctive patterns of abilities, interests, and personality profiles. Third, academic environments differentially socialize students toward the acquisition of those abilities, interests, and values that reflect those of the respective environment. Finally, students are most successful in academic environments that are congruent with their dominant personality type (Smart et al., 2006).

Prior higher education research has demonstrated some support for the various tenets (i.e., Chen \& Simpson, 2015; Feldman et al., 1999, 2004, 2008; Feldman et al., 
Journal Committed to Social Change on Race and Ethnicity | Volume 6, Issue 2 | 2020

2001; Huang \& Healy, 1997; Pike, 2006a, 2006b; Porter \& Umbach, 2006; Smart et al., 2006), and findings have largely driven two practical recommendations for guiding college students in their academic and career pursuits. On one end, the congruence assumption of Holland's theory has prompted recommendations to guide college students into the academic majors and careers that match their particular personality type so that students, it is argued, have the greatest chance of long-term success and satisfaction (Smart et al., 2006). On the other end, studies examining the socialization assumption of Holland's theory indicate that although students entering academic environments that are incongruent with their initially prominent characteristics will remain stable or decline in those initially prominent characteristics, these students, scholars argue, will still be "successful" as they will grow in the set of interests, values, and abilities reinforced and rewarded by the academic environment (Smart et al., 2006). Thus, the socialization assumption has guided efforts to not necessarily constrain students' academic choices to their past or present personality profiles (as the congruence assumption recommendation does), but rather to assist students in choosing academic environments where they will have the greatest likelihood of developing the interests, attitudes, competencies, and values they desire in the future (Reardon \& Bullock; 2004; Smart et al., 2006).

On the surface, this framework along with these recommendations may make sense for all students in all fields. However, several scholars have illuminated potential issues with particular recommendations from Holland's theory in light of problematic findings related to student values in STEM majors. For example, studies by Milem and Umbach (2003) and Umbach and Milem (2004) showed that students majoring in realistic, investigative, and enterprising fields (i.e., many STEM disciplines) were less 
Journal Committed to Social Change on Race and Ethnicity | Volume 6, Issue 2 | 2020

likely to indicate plans for participation in diversity activities and seem to hold less favorable views toward diversity, respectively, suggesting that many STEM environments may be more likely to hold and reward negative attitudes about diversity. Additionally, Huang and Healy (1997) found a negative relationship between many STEM majors and students' interest in helping others who are in difficulty. They indicate that since academic majors shape students' values, academic departments may want to review and evaluate those influences on students in relation to departmental and societal goals. Finally, Porter and Umbach (2006) emphasize that encouraging students to choose environments that fit their personality may lead to a conformity of views in those particular environments.

These studies raise important questions about the STEM environment and the values and competencies considered important or peripheral in STEM education in relation to Holland's assumptions. However, research has yet to examine the potential consequences of Holland's framework specifically for the empowerment of USC pursuing STEM fields. Only has Rendón (2006) illuminated problems with using Holland's theory with underserved students highlighting the narrow definition of success used in the framework (which focuses solely on being a good match with a major) and the link between the P-E fit framework and acculturation/assimilation (which locate the problem within the individual and may result in blaming the victim for a lack of success). This study builds on Rendón's (2006) critique raising important questions about this influential framework in relation to the social justice values of USC pursuing STEM degrees. Specifically, the purpose of this study is to explore: (1) whether USC may potentially be more likely to be defined as "incongruent" with the STEM environment as defined by Holland's typology, (2) whether students, particularly USC, who value social 
Journal Committed to Social Change on Race and Ethnicity | Volume 6, Issue 2 | 2020

justice should really choose non-STEM environments in order to be successful (i.e., congruence assumption), and (3) whether the social justice goals of STEM bachelor's degree recipients remain stable or decline over the long-term (i.e., socialization assumption).

\section{Categorization of and Dominant Values in STEM Education}

Holland's typology indicates that academic disciplines can be categorized into six different environments: (1) realistic, or environments that focus on concrete, practical activities that often use machines and tools; (2) investigative, which emphasize activities that focus on the creation and use of knowledge; (3) artistic, or environments that are concerned with creative activities and that emphasize ambiguous, unstructured endeavors; (4) social, which are environments that focus on the healing or teaching of others and emphasize the acquisition of interpersonal competencies; (5) enterprising, which emphasize leadership development and reward popularity, self-confidence, and aggressiveness and are oriented toward personal or organizational goal attainment through leadership or manipulation; and (6) conventional, or environments that focus on meeting requirements or needs through the use of numbers or machines, emphasize a conventional outlook and are concerned with orderliness and routines (Smart et al., 2000). Academic departments are typically classified into Holland's $(1985,1997)$ six environments using either the Dictionary of Holland Occupational Codes (Gottfredson \& Holland, 1996) or The College Majors Finder (Rosen et al., 1989), and STEM departments are primarily categorized as realistic, investigative, or enterprising environments under Holland's typology. Specifically, STEM majors that are considered realistic environments include electrical engineering, mechanical engineering, and marine science. Biology, civil engineering, chemical engineering, chemistry, earth 
Journal Committed to Social Change on Race and Ethnicity | Volume 6, Issue 2 | 2020

science, physics, statistics, biochemistry/biophysics, aeronautical/astronautical engineering, atmospheric science, and mathematics (among others) are STEM majors categorized as investigative, while industrial engineering and computer science are STEM majors considered enterprising environments (see Feldman et al., 1999).

Within the postulates of Holland's theory, the acquisition of interpersonal competencies and notions of helping others are not considered part of STEM environments, and some STEM environments, specifically those categorized as enterprising, emphasize and reward "aggressiveness," neither of which are critiqued in Holland's framework. The only STEM-related major categorized as a "social" environment in Holland's typology is nursing (see Feldman et al., 1999). These categorizations of STEM environments connect to the literature on STEM undergraduate education. For example, research has shown that entering freshmen intending to major in a STEM discipline score lower than their non-STEM counterparts in their goal of becoming a community leader, desire to keep up with or engage in politics, and desire to understand other countries and cultures (Nicholls et al., 2007). Garibay (2015) found that, on average, STEM students have lower social agency and view the importance of working for social change as less important to their career goals than non-STEM undergraduates at the end of college. Additionally, engineering undergraduates have shown to express less of a commitment to both social action (Sax, 2000) and promoting racial understanding, and to be more likely to believe that individuals cannot change society (Astin, 1993).

While STEM education research seems to support the categorization of STEM disciplines by Holland's framework, too often these characteristics of the environment are accepted without acknowledging that the environment is defined by the dominant 
Journal Committed to Social Change on Race and Ethnicity | Volume 6, Issue 2 | 2020

group, and national statistics on the STEM professoriate show that the majority of STEM faculty are white men (NSF, 2011). Moreover, the characteristics of the environment are accepted without question resulting in an advising approach where the onus is placed on the "person" in the person-environment fit framework to either change or leave STEM to achieve "fit." Might USC have different motivations for pursuing STEM fields than their white counterparts that do not align with the dominant STEM environment as categorized by Holland's typology?

\section{Racial/Ethnic Differences in Motivations for Pursuing STEM}

More recently, researchers have begun to specifically examine the values and motives of USC in STEM revealing a more nuanced understanding of how these STEM students' social justice orientations, along with their interests in STEM, often drive their career pursuits (Garibay, 2015, 2018; Carlone \& Johnson, 2007; Charleston, 2012; McGee \& Bentley, 2017; Newman, 2011). For example, Newman (2011) found that many African American engineering and computer science students pursue their fields with goals of working for social justice. Additionally, Carlone and Johnson's (2007) science identity theory, based on a multi-year ethnographic study of Women of Color (WOC) in the sciences, reveals that many WOC view their pursuit of science careers as a service to humanity and a "vehicle for altruistic ambitions" (p. 1199). Furthermore, Garibay's (2015) national study of over 6,100 undergraduates showed that compared to their non-USC STEM peers, USC in STEM reported that working for social change was significantly more important to their career goals.

These motivations, however, can result in disrupted trajectories for USC in STEM. Johnson (2007) found that WOC at a predominantly white institution described a conflict between their altruistic motivations for pursuing science and their professor's 
Journal Committed to Social Change on Race and Ethnicity | Volume 6, Issue 2 | 2020

valuing science in and of itself. Additionally, McGee and Bentley's (2017) study reveals the challenges many black and Latinx students face related to working for social justice within STEM fields, noting that few of these students believed they could fully reconcile their goals of working for social justice with a STEM career.

Previous studies provide an important foundation for understanding how the dominant culture of many STEM environments may not ostensibly support the commitment to social change espoused by many USC pursuing STEM degrees, which raises important issues with the environment-end of the person-environment fit framework. Might the manner in which Holland's framework is utilized be more likely to categorize USC as incongruent with the STEM environment? Additionally, the question of whether students who value social justice should choose non-STEM environments in order to be more "successful" remains, as research has yet to fully explore differences in goals of working for social change among academically successful STEM graduates at multiple time points and different post-college trajectories. Furthermore, much is unknown about how social justice goals change over the long-term for STEM bachelor's degree recipients, which would help to evaluate recommendations based on Holland's socialization assumption as they relate to USC in STEM. These are some of the gaps this study will aim to address.

\section{Challenging Traditional Notions of STEM Student Success Through Quantitative Criticalism}

A quantitative criticalist stance (Stage, 2007) is used in this study to assess the applicability and implications of Holland's framework for USC in STEM. Quantitative criticalism seeks to "forge challenges, illuminate conflict, and develop critique through quantitative methods in an effort to move theory, knowledge, and policy to a higher 
Journal Committed to Social Change on Race and Ethnicity | Volume 6, Issue 2 | 2020

plane" (Stage, 2007, p. 8). A critical quantitative research design informed the study in several ways. First, to reveal and identify inconsistencies with the applicability of Holland's framework for USC pursuing STEM degrees over the long-term, a national longitudinal dataset of academically successful USC in STEM that spans seven years was used. Prior Holland-based studies in the higher education literature have largely used cross-sectional data from only one institution (e.g., Chen \& Simpson, 2015; Milem \& Umbach, 2003; Umbach \& Milem, 2004; Pike, 2006a, 2006b), longitudinal data from a single institution (e.g., Porter \& Umbach, 2006), or national longitudinal samples covering four years of college starting in the mid-1980s (e.g., Feldman et al., 1999, 2001, 2004; Huang \& Healy, 1997; Smart et al., 2006), resulting in important methodological limitations including relatively small samples of USC in STEM. Leveraging a more recent national longitudinal sample of STEM bachelor's degree recipients over seven years (from their freshman year in 2004 to 2011) with a large sample of USC allows the study to better represent links between current and diverse student interests and their long-term success.

Second, the study separated USC from white students in the analyses to allow the results to better represent "the misrepresented" and reveal flaws in normative research practices where the norm is white students (Stage, 2007). Finally, to conduct culturally relevant research the study contextualizes the measures, analytic practices, and findings to the larger sociopolitical realities of USC. Specifically, the study moves beyond prioritizing economic-centered perspectives that have largely framed the purpose of STEM education and definitions of STEM student success with respect to the need to maintain U.S. global competitiveness (e.g., National Academy of Sciences, 2007; National Science Board, 2004; President's Council of Advisors on Science and 
Journal Committed to Social Change on Race and Ethnicity | Volume 6, Issue 2 | 2020

Technology, 2012), and instead centers the lives and racial realities of USC, where severe poverty and inequities continue to disproportionately impact People of Color (Semega et al., 2019). By centering these realities important measures of student success move beyond simply acquiring STEM knowledge, developing STEM competencies, and earning STEM degrees to also include the importance of developing marginalized students' transformative potential to critique and improve the conditions of their lives using science and mathematics (Calabrese Barton, 2001; Frankenstein, 1983; Gutstein, 2006; Martin, 2003). Thus, this study focuses on STEM students' social agency, or their interest in promoting a more equitable society through social action.

To highlight these issues, I center the analysis on a latent variable that many Holland-based studies have called the "social" personality in Holland's framework (i.e., Chen \& Simpson, 2015; Feldman et al., 1999, 2004, 2008; Feldman, et al., 2001; Porter \& Umbach, 2006; Smart et al., 2006). However, the term "social agency" is used in this study to refer to the factor, given that this is currently the term used by the Cooperative Institutional Research Program (CIRP) and HERI (see Sharkness et al., 2010, p. 32), which administered the data used in this study (as well as many Holland-based studies in higher education). Though both terms have their limitations, "social agency" is a more appropriate term as the items that make up the factor relate to one's interest in being socio-politically active to improve society. While calling the factor social agency may disconnect it from Holland's framework, the wide use of CIRP data and this particular latent variable in research on Holland's framework suggests that it does measure Holland's "social" personality. Highlighting the socio-political nature of the factor is central to this study, yet other Holland-based STEM studies have not emphasized this aspect of the factor. Thus, using the term "social agency" allows for better 
Journal Committed to Social Change on Race and Ethnicity | Volume 6, Issue 2 | 2020

understanding the implications of this outcome for student empowerment and definitions of success related to USC pursuing STEM fields. The following sections describe the research questions, hypotheses, and methodology that were informed by quantitative criticalism.

\section{Research Questions and Hypotheses}

In higher education research, scholars apply Holland's notion of congruence/incongruence by largely treating academic environments as fixed and use students' personalities and interests to determine "fit" (Rendón, 2006). Research has yet to examine whether USC may be more likely to be deemed as "incongruent" ${ }^{2}$ with the STEM environment (as categorized by Holland's framework) based on a particular orientation (e.g., social agency) $)^{3}$ even if they were ultimately successful academically by earning a STEM bachelor's degree and pursuing post-college STEM environments (such as the STEM workforce or STEM graduate programs). Thus, the first research question focuses on whether there are significant differences in social agency between USC and their white peers at two time points first among all STEM bachelor's degree

\footnotetext{
${ }^{2}$ It is important to note that there is not one specific way as to how to classify students as "incongruent" with a particular environment. Past Holland-based studies have examined students' personalities differently. Some have assigned students to a personality type based on the personality for which they had the highest scale score in their freshman year (Feldman et al., 2004), while others have included various personalities as covariates into the same model to examine the linear relationship between these personality scores and enrolling in a STEM major (Chen \& Simpson, 2015). This study examines social agency differences based on race/ethnicity to illuminate which students may be more likely to be classified as "incongruent" with STEM and critiques the notion of incongruence related to social agency and STEM degrees/careers given the importance of developing the social agency of Underrepresented Students of Color.

${ }^{3}$ The purpose of this analysis is not to show that being high on social agency means they are low on realistic, enterprising, and investigative (REI) dimensions. The concern here is not to test students' realistic, enterprising, and investigative dimensions as prior studies have shown the relationship of these dimensions to pursuing a STEM major. Rather, I am examining whether there are differences among these successful STEM bachelor's degree earners, particularly in social agency by race/ethnicity, to shed light on potential racial/ethnic inequities that may result.
} 
Journal Committed to Social Change on Race and Ethnicity | Volume 6, Issue 2 | 2020

recipients, then among those in STEM graduate/professional programs, and finally among those in the STEM workforce.

Research Question 1: Are there differences in social agency between USC and their white counterparts (at college entry and several years after college) among all STEM bachelor's degree recipients as well as those who are in different postundergraduate STEM environments, specifically those who are enrolled in or completed a STEM graduate/professional program and those who entered into the STEM workforce?

Given that prior research has shown that USC often articulate democratic goals for pursuing STEM (Carlone \& Johnson, 2007; Garibay, 2015; McGee et al., 2016; Newman, 2011), it is hypothesized that USC will have higher social agency at multiple time points among all STEM bachelor's degree earners, among those in STEM graduate/professional programs, and among those in the STEM workforce and thus, be more likely to be considered "incongruent" with the various STEM environments (undergraduate majors, graduate programs, and STEM workforce) as categorized by Holland's typology.

Research question 2 evolves out of Holland's supposition that individuals who are deemed incongruent with STEM environments (i.e., have higher social agency) are less likely to be successful over the long-term in those environments. Prior studies, however, have yet to investigate the utility of this supposition for understanding postcollege pathways (i.e., non-STEM post-undergraduate pathway, STEM workforce, and STEM graduate program) among students who graduated with STEM bachelor's degrees. Thus, research question 2 explores whether students who ultimately pursued different post-undergraduate pathways had different levels of social agency in their 
Journal Committed to Social Change on Race and Ethnicity | Volume 6, Issue 2 | 2020

freshman year, with a particular focus on whether the results are different for USC and white students.

Research Question 2: Among STEM bachelor's degree recipients who are in different post-undergraduate pathways, does freshman social agency differ for USC and white students, respectively?

It is expected that STEM bachelor's degree recipients who pursue non-STEM pathways after their undergraduate years will have higher social agency at the start of college compared to those who pursue STEM pathways. However, given research that has shown a connection between many graduate students' racial/ethnic identity and their social justice motivations for pursuing STEM careers (Carlone \& Johnson, 2007; McGee et al., 2016), it is hypothesized that Holland's congruence assumption may not completely fit USC pursuing STEM-graduate programs.

Finally, the third research question seeks to investigate Holland's socialization assumption by examining long-term changes in social agency, an orientation deemed "incongruent" with the STEM environment as defined by Holland's framework. The socialization assumption of Holland's theory indicates that students' initially prominent characteristics that are not valued or rewarded in the STEM environment will stay the same or even reduce. This is examined separately for USC and white students.

Research Question 3: How does the social agency of STEM bachelor's degree recipients who are USC and white change over the long-term? Given that STEM environments are primarily categorized as realistic, investigative, and enterprising environments, and prior literature highlighting the limitations of STEM education with respect to the development of students' social and civic responsibility (Astin, 1993; Beckwith \& Huang, 2005; Garibay, 2015; Sax, 2000; 
Journal Committed to Social Change on Race and Ethnicity | Volume 6, Issue 2 | 2020

Vaz, 2005), it is hypothesized that STEM bachelor's degree recipients' social agency will not increase over the long-term.

\section{Methodology}

\section{Data Source and Sample}

This study uses longitudinal student data from the 2004 Cooperative Institutional Research Program's (CIRP) Freshman Survey (TFS) and the 2011 Post-Baccalaureate Survey (PBS). The TFS survey was administered in the fall of 2004 to entering freshmen, while the PBS was administered in 2011. The 2004 TFS collected information about students' background characteristics, pre-college experiences and achievement, expectations for college, attitudes, values and future educational and career goals, while the PBS gathered information about participants' undergraduate experiences, perceptions, and posttest data on many of the attitudinal and behavioral items collected on the 2004 TFS. Grants from the National Institutes of Health $(\mathrm{NIH})$ and the National Science Foundation (NSF) helped target additional institutions in the collection of data, including Minority-Serving Institutions and colleges known for graduating large numbers of undergraduate students with STEM degrees, which allowed the study to yield a large percentage of students who started out as STEM aspirants. In total, 13,671 students responded to both surveys, which resulted in a response rate of $23.7 \%$. To reduce the effect of nonresponse bias, nonresponse weights were applied to the data to adjust the PBS sample of respondents upward to look more like the original target sample of TFS respondents.

The sample for this study is limited to STEM bachelor's degree recipients (see Appendix A for a list of majors defined as STEM) who identified as American Indian/Alaska Native, Black/African American, Latina/o, or white who had data available 
Journal Committed to Social Change on Race and Ethnicity | Volume 6, Issue 2 | 2020

for the dependent variables: 2004 and 2011 social agency. The final analytic sample consisted of 5,564 STEM bachelor's degree recipients where $78.7 \%$ are white and 21.3\% are USC (i.e., American Indian/Alaska Native, Black/African American, and Latina/o), which is comparable to recent national figures showing that $21 \%$ of science and engineering bachelor's recipients are USC (NSF, 2017). Of the STEM bachelor's degree recipients in the sample, 1,936 STEM bachelor's degree recipients had enrolled in or completed a STEM graduate or professional program, 1,200 had entered the STEM workforce (without having entered into a graduate/professional program), and 2,424 were in a non-STEM post-undergraduate pathway (i.e., non-STEM graduate/professional program or workforce).

\section{Variables}

The dependent variables for this study are the 2004 and 2011 social agency factors, which consist of five items on the 2004 TFS and 2011 PBS instruments, respectively. These measures were examined separately for the first two research questions and together make up the dependent variable for the multilevel model for repeated measures (research question 3), which are further described in the analyses subsection below. Students were asked to report how important "helping to promote racial understanding," "becoming a community leader," "participating in a community action program," "helping others in difficulty," and "influencing social values" is to them. The factor holds the same name as the CIRP construct of social agency, but only contains five of the six items in the construct as only these five items were included as part of the 2011 PBS instrument. Table 1 presents the factor loadings and reliability coefficients (Cronbach's alpha) for the social agency factors. The factor was scored using classical test theory and factor loadings were computed using principal axis 
Journal Committed to Social Change on Race and Ethnicity | Volume 6, Issue 2 | 2020

factoring with promax rotation.

The variables comprising the social agency factor capture various competencies and outcomes that many STEM education scholars have contended are critical toward promoting equity beyond STEM, including an understanding of social issues (Baillie et al., 2011), as well as civic and social responsibility, civic awareness, and civic engagement (e.g., Jordan, 2006; Lima, 2000; Vaz, 2005). The specific action-oriented items on racial issues, being a community leader, and participating in a community action program also engage the notion of altering power relations and structural barriers that many STEM scholars (i.e., Calabrese Barton \& Tan, 2011; Gutstein, 2006; Martin, 2003; Tate, 1995) argue is necessary to achieve social justice for Students of Color. Overall, the set of questions demonstrate whether a student believes being active sociopolitically to improve society is important to her or his life. Each item in the factor is coded on a 4-point ordinal scale ( $1=$ Not Important to $4=$ Essential) and higher values in the factor suggest a greater level of social agency.

Table 1. 2004 and 2011 Social Agency

\begin{tabular}{|c|c|c|c|c|}
\hline & \multicolumn{2}{|c|}{2004} & \multicolumn{2}{|c|}{2011} \\
\hline & Alpha & Loading & Alpha & Loading \\
\hline Social Agency & 0.783 & & 0.837 & \\
\hline Participate in a community action program & & 0.755 & & 0.793 \\
\hline Helping to promote racial understanding & & 0.676 & & 0.730 \\
\hline Becoming a community leader & & 0.645 & & 0.728 \\
\hline Influencing social values & & 0.610 & & 0.695 \\
\hline Helping others in difficulty & & 0.557 & & 0.614 \\
\hline
\end{tabular}

Note. Students responded to the prompt "Indicate the importance to you personally of each of the following" using a scale of $1=$ Not Important, 2=Somewhat Important, 3= Very Important, 4= Essential 
Journal Committed to Social Change on Race and Ethnicity | Volume 6, Issue 2 | 2020

\section{Analyses}

Research Question 1. To help understand whether USC are more likely to be considered "incongruent" with STEM environments, $t$-tests were performed to compare USC to white students on their freshman social agency and social agency scores seven years after entering college. These tests were performed first for all STEM bachelor's degree recipients, then for those STEM bachelor's degree recipients who were enrolled in or had completed a STEM graduate or professional program, and then for STEM bachelor's degree recipients who had entered into the STEM workforce (and had not enrolled in a graduate/professional program) to help understand differences between USC and their white counterparts in various STEM contexts.

Research Question 2. According to Holland's framework, individuals who are incongruent with their environment are less likely to be successful long-term in that environment. To help examine this supposition in relation to students' social agency, ANOVAs were used to examine whether STEM bachelor's degree recipients who pursued different post-undergraduate pathways differed on their freshman-year social agency. This analysis was conducted separately for USC and white students to understand whether this supposition may help understand long-term success for these two groups. The three post-undergraduate pathways examined were those who (1) were enrolled in or completed a STEM graduate/professional program, (2) entered the STEM workforce and had not enrolled in a graduate/professional program, and (3) pursued a non-STEM pathway.

Research Question 3. The sociological component of Holland's framework indicates that individuals who enter particular academic environments are likely to stay the same or decline in those values and interests not valued or rewarded in the chosen 
Journal Committed to Social Change on Race and Ethnicity | Volume 6, Issue 2 | 2020

academic environment. To examine whether USC and white students who graduated with STEM bachelor's degrees changed in their social agency between their freshman year and seven years later, multilevel modeling for repeated measures was conducted using the HLM 6.01 program. Repeated measures data can be understood as having a multi-level structure in which subjects have been sampled first, and measures have been sampled within subjects (Van Der Leeden, 1998). Thus, the observations are not all independent as observations are clustered, or nested, within individuals, and observations within the same individual tend to be correlated (Van Der Leeden, 1998). Multilevel modeling for repeated measures has several advantages over repeated measures ANOVA, including having less stringent assumptions (i.e., assumptions of homogeneity of variances, constant covariances, and constant variances of differences scores are not necessary), and disaggregation of higher-level units into a single-level model results in an underestimation of the Type I error (Raudenbush \& Bryk, 2002; Snijders \& Bosker, 1999).

The fully unconditional model (null model) for the USC and white group showed that most of the variance was attributed to the observation level. The intraclass correlation coefficient (ICC) showed that $40.13 \%$ and $41.01 \%$ of the total variance in students' social agency scores was situated at the individual level for USC and white STEM bachelor's degree recipients, respectively. Considering the ICC results, a conditional multilevel model was run by modeling Time. Utilizing Raudenbush and Bryk's (2002) levels formulation for presenting a multilevel model for repeated measures, the level 1 equation, or within-subject model, is represented as:

$$
Y_{i j}=\pi 0 i+\pi{ }_{1 i} a_{i j}+e_{i j}
$$


Journal Committed to Social Change on Race and Ethnicity | Volume 6, Issue 2 | 2020

where $Y_{i j}$ is the observed social agency at time $i$ for subject $j,(j=1, \ldots, n), \pi 0 i$ is the intercept parameter and represents the level of social agency of person $j$ at $a_{i j}=0$ (freshman year), $\pi_{1 i}$ is the growth rate for subject $j$ over the data-collection period and represents the expected change during a fixed unit of time, and $e_{i j}$ represents error terms which can be assumed to be independent and normally distributed with a mean of 0 and constant variance. The time variable, $a_{i j}$, is not centered.

The level 2 or between-subject model is:

$$
\begin{aligned}
& \pi_{0 i}=\gamma_{00}+U_{0 i} \\
& \pi_{1 i}=\gamma_{10}
\end{aligned}
$$

where yoo represents the mean intercept (the intercept parameter is allowed to vary at level 2), the random effect $u_{0 i}$ has a variance of $\mathrm{T}_{00}$, and $\mathrm{\gamma}_{10}$ represents the mean growth rate.

\section{Limitations}

This study is limited in several ways. First, the data are limited in their generalizability as CIRP data is not fully representative of college students or the range of US higher education institutions types. Even though the data come from a national and diverse sample of college students, any generalizations beyond the sample should be made with caution. Second, the study uses a narrow definition of STEM by examining and often referring to STEM majors as a general group as well as not accounting for many interdisciplinary and multidisciplinary degrees that are emerging in STEM (i.e., sustainability, bio-mechanical engineering, etc.). As with any study using secondary data, the study is limited by the variables available on the surveys and was unable to fully explore this increasing complexity of STEM degrees. While academic major categories do not capture this complexity in this collection of the CIRP Freshman 
Journal Committed to Social Change on Race and Ethnicity | Volume 6, Issue 2 | 2020

Survey and Post-Baccalaureate Survey, the Integrated Postsecondary Education Data System, which is the primary source for data on colleges and universities in the U.S., also does not account for this complexity with their Classification of Instructional Programs (CIP) codes between 2000 and 2010 (see U.S. Department of Education National Center for Education Statistics, n.d.).

Third, the study does not disaggregate USC nor does it disaggregate students by their STEM major. Generalizations about all STEM majors and racial/ethnic groups should be made with caution as variation exists within each of these categories.

Statistical differences between groups should always be interpreted with caution as they do not explain why such differences might exist or address the meaningfulness of any statistical difference. Explaining why differences may exist between groups is certainly important and will be addressed briefly in this manuscript but a more involved discussion is beyond the scope of the study. Finally, while measures at two time points have been used in prior studies to observe change over time, two wave data present several limitations (e.g., one cannot distinguish "real" individual differences in change from error, less power and reliability of individual growth parameters) and thus future research should use multiwave longitudinal data (more than two measurement occasions) to yield better determinations of individual change (Rogosa et al., 1982).

\section{Results}

\section{Social Agency Comparisons between USC and White Groups: Who is}

"Incongruent"? To examine whether Underrepresented Students of Color and white students were associated with statistically significantly different means for their 2004 and 2011 social agency, a series of independent samples $t$-tests were performed. Table 2 presents the means, standard deviations, and results of the $t$-tests. First, these tests 
Journal Committed to Social Change on Race and Ethnicity | Volume 6, Issue 2 | 2020

were performed for all STEM bachelor's degree recipients. The USC group $(N=1,184)$ was associated with a 2004 social agency of $M=0.3475$ ( $S D=0.9624)$. By comparison, the white group $(N=4,380)$ was associated with a numerically lower 2004 social agency score $M=-0.1458(S D=0.8305)$. To test the hypothesis that USC and white students were associated with statistically significantly different mean 2004 social agency, an independent samples $t$-test was performed. Given that Levene's $F$ test, $F(20,970)=$ $202.703, p=.000$ revealed that the assumption of homogeneity of variances was not satisfied, Welch's $t$-test was used. The adjusted independent samples $t$-test was associated with a statistically significant effect, $t(8,503.51)=-33.728, p<.001$. Thus, USC were associated with a statistically significantly higher 2004 social agency than white students. Similarly, Welch's $t$-test for 2011 social agency revealed a significant effect, $t(8,428.93)=-38.903, p<.001$ showing that USC had statistically significantly higher 2011 social agency than white STEM bachelor's degree recipients.

Second, these tests were performed for those STEM bachelor's degree recipients who were enrolled in or had completed a STEM graduate or professional program. The USC group ( $N=357)$ was associated with a numerically higher 2004 social agency score $M=0.3860(S D=0.9431)$ than white students $(N=1,579) M=-0.1364(S D=$ 0.8204). The adjusted independent samples $t$-test was associated with a statistically significant effect, $t(2,120.49)=-19.259, p<.001$, which indicates that USC had statistically significantly higher 2004 social agency scores than their white counterparts who were enrolled in or had completed a STEM graduate or professional program. These two groups had statistically significantly different 2011 social agency scores as well, $t(2,145.74)=-22.432$, and the USC group was associated with higher 2011 social agency. 
Journal Committed to Social Change on Race and Ethnicity | Volume 6, Issue 2 | 2020

Table 2. Means, Standard Deviations, and t-tests: 2004 and 2011 Social Agency Comparisons between USC ${ }^{a}$ and White Groups

\begin{tabular}{|c|c|c|c|c|c|c|}
\hline \multirow[b]{2}{*}{$\begin{array}{l}\text { All STEM Bachelor's } \\
\text { Degree Recipients }\end{array}$} & \multicolumn{3}{|c|}{2004 Social Agency } & \multicolumn{3}{|c|}{2011 Social Agency } \\
\hline & $\begin{array}{l}\text { White } \\
(n=4380)\end{array}$ & $\begin{array}{c}\text { USC } \\
(n=1184)\end{array}$ & t-test(Sig.) & $\begin{array}{c}\text { White } \\
(n=4380)\end{array}$ & $\begin{array}{c}\text { USC } \\
(n=1184)\end{array}$ & t-test(Sig.) \\
\hline Mean & -0.1458 & 0.3475 & $-33.73^{* \star \star}$ & -0.1787 & 0.4031 & $-38.90^{* * *}$ \\
\hline S.D. & 0.8305 & 0.9624 & & 0.8411 & 0.9865 & \\
\hline $\begin{array}{l}\text { Enrolled } \\
\text { in/Completed STEM } \\
\text { Graduate Program }\end{array}$ & $(n=1579)$ & $(n=357)$ & & $(n=1579)$ & $(n=357)$ & \\
\hline Mean & -0.1364 & 0.3860 & $-19.26^{\star * *}$ & -0.1661 & 0.4616 & $-22.43^{* * *}$ \\
\hline S.D. & 0.8204 & 0.9431 & & 0.8588 & 0.9697 & \\
\hline $\begin{array}{l}\text { Pursued STEM } \\
\text { Workforce }\end{array}$ & $(n=988)$ & $(n=212)$ & & $(n=988)$ & $(n=212)$ & \\
\hline Mean & -0.2448 & 0.1698 & $-12.84^{\star \star \star}$ & -0.3587 & 0.0738 & $-12.88^{\star \star *}$ \\
\hline S.D. & 0.8129 & 0.9472 & & 0.7997 & 0.9954 & \\
\hline
\end{tabular}

Note. Data are weighted.

aUSC= Underrepresented Student of Color (American Indian/Alaska Native, Black/African American, and Latina/o)

${ }^{*} p<0.05 .{ }^{* *} p<0.01 .{ }^{* * *} p<0.001$

Third, independent samples $t$-tests were performed for those STEM bachelor's degree recipients who had entered into the STEM workforce. Welch's $t$-tests for both the 2004 and 2011 social agency scores showed that the USC group $(N=212)$ compared to the white group ( $N=988$ ) was associated with statistically significantly higher social agency in both 2004, $t(1,463.95)=-12.844, p<.001$, and $2011, t(1,408.05)=$ $-12.88, p<.001$.

\section{Does Freshman Social Agency Differ by Post-Undergraduate Pathways for}

USC and White Groups? To examine whether there were differences in freshman social agency between STEM bachelor's degree recipients by post-undergraduate pathway, one-way ANOVAs were conducted separately for USC and white groups. Table 3 presents the results of the one-way ANOVAs. The three post-undergraduate 
Journal Committed to Social Change on Race and Ethnicity | Volume 6, Issue 2 | 2020

pathways examined were those who (1) were enrolled in or completed a STEM graduate/professional program, (2) entered the STEM workforce and had not enrolled in a graduate program, and (3) pursued a non-STEM pathway. For the USC group, the Levene test for the homogeneity of variance revealed equality of variances across postundergraduate pathways $(2.670, d f=5,450, p=.069)$. One-way ANOVA findings showed that we can reject the null hypothesis that freshman social agency was the same across all three groups. Post-hoc analyses, which are presented in Table 4, showed that freshman social agency was significantly lower for those who pursued the STEM workforce compared to a STEM graduate or professional program and those who pursued a non-STEM pathway. Importantly, there was no statistically significant difference in freshman social agency between those USC who pursued a non-STEM pathway compared to a STEM graduate or professional program.

Table 3. ANOVAs: 2004 Social Agency by Post-Undergraduate Pathway for USC ${ }^{a}$ and White STEM Bachelor's Degree Recipients

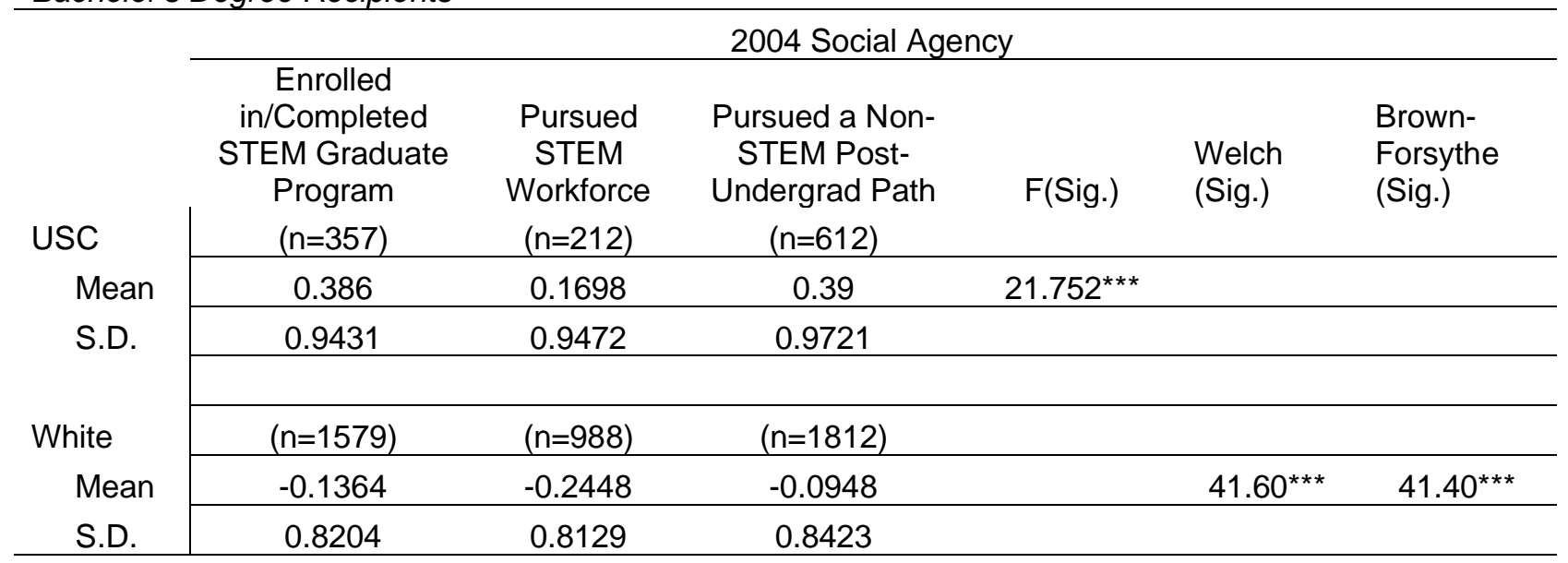

Note. Data are weighted.

aUSC= Underrepresented Student of Color (American Indian/Alaska Native, Black/African American, and Latina/o)

${ }^{*} p<0.05 .{ }^{* *} p<0.01 .{ }^{* * *} p<0.001$ 
Journal Committed to Social Change on Race and Ethnicity | Volume 6, Issue 2 | 2020

To test whether freshman social agency was similar across post-undergraduate pathways for white students, Welch's and Brown-Forsythe's tests were used given that Levene's statistic for the homogeneity of variance revealed unequal variances ( 3.452 , $d f=15,482, p<.05)$. Welch's test $(41.595, d f=9,410.91, p<.001)$ and Brown-Forsythe's test $(41.401, d f=14,226.94, p<.001)$ showed that we could reject the null hypothesis that freshman social agency was the same across the three groups. In contrast to findings for the USC group, post-hoc tests showed additional differences across postundergraduate pathways for the white group (see Table 4). For the white group, there were statistically significant differences across all three groups. Those who pursued a non-STEM pathway had the highest freshman social agency scores, those who pursued a STEM graduate/professional program had the second highest, and those who entered the STEM workforce had the lowest.

Table 4. Post-hoc Analyses of Freshman Social Agency for USC a and White Groups

\begin{tabular}{|c|c|c|c|c|c|c|c|c|c|}
\hline & \multicolumn{9}{|c|}{2004 Social Agency } \\
\hline & $\begin{array}{l}\text { STEM } \\
\text { Grad or } \\
\text { Prof }\end{array}$ & $\begin{array}{l}\text { STEM } \\
\text { Work }\end{array}$ & Sig. & $\begin{array}{l}\text { STEM } \\
\text { Work }\end{array}$ & $\begin{array}{l}\text { Non- } \\
\text { STEM } \\
\text { Path }\end{array}$ & Sig. & $\begin{array}{l}\text { STEM } \\
\text { Grad or } \\
\text { Prof }\end{array}$ & $\begin{array}{l}\text { Non- } \\
\text { STEM } \\
\text { Path }\end{array}$ & Sig. \\
\hline USC & $(n=357)$ & $(n=212)$ & & $(n=212)$ & $(n=612)$ & & $(n=357)$ & $(n=612)$ & \\
\hline Mean & 0.3860 & 0.1698 & $\star * *$ & 0.1698 & 0.39 & $\star \star \star *$ & 0.386 & 0.39 & \\
\hline S.D. & 0.9431 & 0.9472 & & 0.9472 & 0.9721 & & 0.9431 & 0.9721 & \\
\hline White & $(n=1579)$ & $(n=988)$ & & $(n=988)$ & $(n=1812)$ & & $(n=1579)$ & $(n=1812)$ & \\
\hline Mean & -0.1364 & -0.2448 & $* * *$ & -0.2448 & -0.0948 & $* * *$ & -0.1364 & -0.0948 & ** \\
\hline S.D. & 0.8204 & 0.8129 & & 0.8129 & 0.8423 & & 0.8204 & 0.8423 & \\
\hline
\end{tabular}

Note. Data are weighted

Note. Sheffe test used for USC, Games-Howell test used for White Group aUSC = Underrepresented Student of Color (American Indian/Alaska Native, Black/African American, and Latina/o)

${ }^{*} p<0.05 .{ }^{* *} p<0.01$. ${ }^{* * *} p<0.001$ 
Journal Committed to Social Change on Race and Ethnicity | Volume 6, Issue 2 | 2020

\section{How Does Social Agency Change for STEM Bachelor's Degree Recipients}

Over the Long Term? Table 5 presents the results of the multilevel model for repeated measures for both the USC and white groups. For the USC model, the tests of fixed effects indicate that the mean intercept $(0.2919)$ differs significantly from $0, t(1,183)=$ $5.046, p<.001$ and that the mean slope $(b=0.0556)$ does not differ significantly from 0 . The latter finding indicates that there was not a statistically significant change in social agency over the seven years for those STEM bachelor's degree recipients who were USC. The tests of random effects show that the variance of the intercepts for the 1,184 subjects $(0.3804)$ is significantly greater than $0, X^{2}(1,183)=2,762.33, p<.001$. That is, there is evidence of individual differences among the subjects.

Table 5. HLM for Repeated Measures: Social Agency Growth Between 2004-2011

\begin{tabular}{|c|c|c|c|c|}
\hline & \multicolumn{2}{|c|}{$\operatorname{USC}^{a}(n=1,184)$} & \multicolumn{2}{|c|}{ White $(n=4,380)$} \\
\hline & B & S.E. (Sig) & $\mathrm{B}$ & S.E. (Sig) \\
\hline \multicolumn{5}{|l|}{ Variables } \\
\hline Time & 0.056 & 0.035 & -0.033 & $0.015^{*}$ \\
\hline Intercept & 0.292 & $0.058^{* * *}$ & -0.113 & $0.025^{\star \star *}$ \\
\hline \multicolumn{5}{|l|}{ Model Statistics } \\
\hline Level 1 variance & 0.570 & & 0.416 & \\
\hline Level 2 variance & 0.380 & & 0.282 & \\
\hline $\begin{array}{l}\text { Random L-1 intercept } \\
\text { reliability }\end{array}$ & 0.572 & & 0.576 & \\
\hline \multicolumn{5}{|c|}{$\begin{array}{l}\text { Note. Data are weighted. } \\
\text { aUSC= Underrepresented Student of Color (American Indian/Alaska Native, Black/African } \\
\text { American, and Latina/o) } \\
{ }^{*} p<0.05 .{ }^{* *} p<0.01 .{ }^{* \star *} p<0.001\end{array}$} \\
\hline
\end{tabular}

For white STEM bachelor's degree recipients, the tests of the fixed effects indicate that the mean intercept $(-0.1129)$ differs significantly from $0, t(4,379)=-4.467$, $p<.001$ and that the mean slope $(b=-0.0329)$ differs significantly from $0(p<.05)$ and is negative. This indicates that there was a statistically significant decrease in social 
Journal Committed to Social Change on Race and Ethnicity | Volume 6, Issue 2 | 2020

agency for white STEM bachelor's degree recipients over the seven years. The tests of random effects indicate that the variance of the intercepts for the 4,380 subjects $(0.2823)$ is significantly greater than $0, X^{2}(4,379)=10,317.49, p<.001$. That is, there is evidence of individual differences among the subjects.

\section{Discussion}

While Holland's theory has provided a useful framework for many higher education researchers examining college major access and success, this study considers how this framework can potentially create and/or perpetuate conditions that lead to inequity for Students of Color in STEM (Bensimon \& Bishop, 2012). Leveraging a unique national longitudinal sample of STEM bachelor's degree recipients and utilizing quantitative criticalism, this study set out to expand Rendón's (2006) questions about the applicability of Holland's framework to understanding the holistic success of USC in STEM. By centering the racial and sociopolitical realities of People of Color, this study moves beyond solely academic measures of success and instead illuminates the importance of student empowerment. The study's findings reveal some concerning issues that may result when using Holland's framework to inform our understanding of USC success in STEM.

Findings show that among STEM bachelor's degree recipients, USC may be more likely to be defined as "incongruent" with STEM environments under the premises of Holland's theory given their higher pre-test and post-test social agency scores compared to their white counterparts. Their white peers, on the other hand, seem more likely to fit the personality profile of STEM environments as defined by Holland's typology by having lower social agency, which may result in a greater proportion of white students being defined as "congruent" with STEM environments. According to the 
Journal Committed to Social Change on Race and Ethnicity | Volume 6, Issue 2 | 2020

congruence assumption of Holland's theory, students are most likely to be successful in academic environments that have the same label because these environments would provide opportunities, activities, tasks, and roles congruent with the competencies, interests, and self-perceptions of its parallel personality type. Thus, academic advisors and career counselors guided by the congruence assumption of person-environment fit would be expected to "counsel" a disproportionate number of USC to "wisely" pursue non-STEM majors and careers. This is problematic and may lead to inequitable outcomes for USC in STEM, reflecting elements of structural racism in STEM (McGee, 2020) where USC are positioned as in need of "fixing." If students who have higher social agency at the onset of college or are seeking to develop these interests during college are encouraged by career counselors to pursue non-STEM fields based on these interests, it is likely to be greater proportions of USC being guided away from STEM majors.

The findings from this study also indicate that the practice of guiding students with higher social agency away from STEM (because it is thought that these students will be less successful in STEM) has the potential to falsely represent the academic success of USC in STEM fields. USC who entered or had completed a STEM graduate/professional program did not have significantly different freshman social agency scores compared to those USC who pursued non-STEM post-undergraduate pathways. In other words, many USC who have high social agency do continue on STEM pathways after college even though they are predicted to leave according to the congruence assumption. This finding is important because it provides a more nuanced understanding of the post-undergraduate trajectories of STEM bachelor's degree 
Journal Committed to Social Change on Race and Ethnicity | Volume 6, Issue 2 | 2020

recipients who are USC and whether the congruence assumption is fully applicable to all students and pathways.

This study did find some evidence in line with the congruence assumption for white students as the freshman social agency scores for those white students who ultimately pursued non-STEM post-undergraduate pathways were significantly higher compared to those who had enrolled or completed a STEM graduate/professional program and those who entered the STEM workforce. Also, USC who entered the STEM workforce had significantly lower freshman social agency scores than their USC peers in non-STEM post-undergraduate pathways and STEM graduate/professional programs. However, as Huang and Healy (1997) suggest, it is important to raise questions about the makeup of STEM environments and the goals of STEM education. Do STEM environments actually want to drive these academically successful students (i.e., STEM bachelor's degree recipients) who have high social agency out of STEM fields? Given that these individuals have a stronger desire to be active socio-politically to improve society, the answer to this question can have important implications for improving the impact of science and technology on the human good.

Moreover, Holland's socialization assumption claims that academic environments differentially socialize students toward the acquisition of values and interests that reflect those of the respective environment. Findings from the multilevel model for repeated measures seemed to support Holland's socialization assumption as the social agency of USC did not change between 2004 and 2011, while that of white students declined over the same time period. These findings connect to prior research on the limitations of STEM education with respect to students' social and civic outcomes (Astin, 1993; Garibay, 2015; Sax, 2000), which have important implications for equity in STEM given 
Journal Committed to Social Change on Race and Ethnicity | Volume 6, Issue 2 | 2020

the relationship between motivations for social justice and STEM career pursuits for Underrepresented Students of Color (Carlone \& Johnson, 2007; Charleston, 2012; Garibay, 2015, 2018; McGee \& Bentley, 2017; Newman, 2011).

\section{Implications}

The results of this study offer several key implications for higher education research, policy, and practice. First, while STEM academic advisors and career counselors may utilize career assessments grounded on Holland's congruence assumption of person-environment fit (e.g., Strong Interest Inventory), the findings of this study suggest that such practices may promote inequitable outcomes for USC in STEM. Categorizing an environment (i.e., STEM) based off of peoples' interest within those environments when those environments are predominantly white, such as in STEM occupations, may introduce bias and inequity to the career advising process. Questions such as "who defines the environment?" (i.e., which demographics are overrepresented in the specific occupation?) and "who does the defining?" (i.e., who developed the parameters for the career assessment measure?) are important to consider when matching USC to careers using traditional career assessment measures.

Second, Holland's congruence assumption may inadvertently promote environments in STEM where a greater proportion of individuals with lower social agency are encouraged to stay and become the principle socialization agents in STEM disciplines. This is likely to further perpetuate a cycle where the dominant STEM environment is unresponsive to the social justice motivations of many USC pursuing STEM majors and careers (Carlone \& Johnson, 2007; Charleston, 2012; Garibay, 2015; McGee \& Bentley, 2017; Newman, 2011). National statistics on the STEM professoriate reveal that the majority of STEM faculty are white males (NSF, 2011), which, as 
Journal Committed to Social Change on Race and Ethnicity | Volume 6, Issue 2 | 2020

Johnson (2007) notes, influences the cultural values espoused within science. If greater proportions of individuals with lower social agency are encouraged to stay in STEM, the values espoused within STEM are likely not to include the development of social agency and altruism, which may lead to conflict between USC and their professors (Johnson, 2007; McGee \& Bentley, 2017). STEM faculty members play a key role in the development of departmental structures and cultures, which ultimately facilitate the success of those who "fit" within those organizational arrangements (Johnson, 2007, Seymour \& Hewitt, 1997).

Third, while the results from the multilevel model for repeated measures seemed to support Holland's socialization assumption with respect to social agency development over the long term, the manner in which the socialization assumption of Holland's theory has been framed and utilized in the field of higher education has important implications for USC in STEM. Feldman et al. (2004) contend that staying the same or declining in one's initially prominent characteristics that are considered "incongruent" with the environment (i.e., social agency) is not problematic given that students will gain in or grow in those abilities and interests reinforced and rewarded by their chosen academic environment (which in STEM would be enterprising, investigative, and realistic). Thus, with this logic it is not considered troublesome that the social agency of STEM bachelor's degree recipients who are USC did not increase and that of white students actually declined over the long-term, but rather is defined as "success" if they grow in those other ways (i.e., enterprising, investigative, and realistic personalities). This seemingly neutral perspective on student success for USC in STEM ignores the racial realities and inequities that People of Color face and the importance of empowering these students to use their STEM knowledge to rectify structural 
Journal Committed to Social Change on Race and Ethnicity | Volume 6, Issue 2 | 2020

inequities. As Martin (2003) states in reference to math education, but I argue may be extended to other STEM fields:

If [marginalized] students are not able to use mathematics knowledge in liberatory ways to change and improve the conditions of their lives outside of school, they will continue to be marginalized... Underrepresented students may experience equal access to mathematics, have equal learning opportunities, and quantitative data could show equal outcomes. However, these students may still be disempowered if they are not able to use mathematics to alter the power relations and structural barriers that continually work against their progress in life. (p. 13-15)

Feldman et al.'s (2004) seemingly neutral perspective also ignores the

importance of changing the culture of STEM education given: (1) the historical legacy of scientific racism and how science and technology have been used in socially and environmentally regressive ways (Hammonds \& Herzig, 2009; Harding, 2006), and (2) the growing body of scholarship critiquing the current culture of mainstream STEM education for not emphasizing the importance of developing students' social justice outcomes (Baillie et al. 2011; Frankenstein, 2012; Garibay, 2015; Gutstein, 2006; Jordan, 2006; Lima, 2000; McGee \& Bentley, 2017; Tate, 1995; Vaz, 2005). Scholars utilizing person-environment fit perspectives in future STEM research should place more emphasis on environmental or organizational change as opposed to seeing those academic environments as static entities where the onus is placed on USC to fit or assimilate into predominantly white organizational cultures (Rendón, 2006).

Furthermore, researchers should not assume STEM academic disciplines are neutral environments that do not play a role in inequity and should contextualize their research to the racial realities and lives of Students of Color beyond higher education.

Finally, while this study highlights the importance of social agency for USC pursuing STEM degrees, it by no means proposes that social agency is the most important factor to consider regarding equity for USC in STEM. That is beyond the 
Journal Committed to Social Change on Race and Ethnicity | Volume 6, Issue 2 | 2020

scope of this research. However, future research in this area can continue to build more sophisticated models integrating the importance of social justice concerns with the growing literature on STEM major access and success for USC (Chang, Sharkness, Hurtado, \& Newman, 2014; Garibay \& Vincent, 2018; Harper \& Newman, 2010; Museus, Palmer, Davis, \& Maramba, 2011; Palmer, Maramba, \& Gasman, 2012).

\section{Conclusion}

By using a critical quantitative approach, this study sheds light on the importance of using a national sample of USC who were academically successful in STEM when trying to understand the utility of theoretical frameworks developed largely using white students, and engaging the political and racial realities of USC beyond higher education when interpreting results. This critical examination of Holland's assumptions, how they have been used to inform higher education policy and practice, and the implications of those assumptions for USC in STEM raises questions about whether personenvironment fit perspectives may lead to inequitable outcomes and the disempowerment of USC in STEM. Not focusing on changing the culture of STEM disciplines to make social justice values more central in various aspects of the environment (i.e., research, teaching, and outreach) places the onus on the student to either conform to the dominant disciplinary culture (i.e., lessen their goals of working for social change) or to find ways to harbor their values of making a difference without critical departmental support while trying to successfully navigate the current dominant STEM culture. Many others may choose to leave STEM fields altogether and pursue an academic environment that values and cultivates their social agency. Thus, unconscious practices of not valuing and fostering students' social justice orientations within STEM may unintentionally create environments that result in educational 
Journal Committed to Social Change on Race and Ethnicity | Volume 6, Issue 2 | 2020

inequalities. Conversely, comprehensively integrating social justice frames into STEM education has the potential to go a long way in helping to address problematic STEM disciplinary cultures, empower USC in STEM to use their STEM knowledge to critique and rectify structural inequities, and help improve the impact of science and technology on social equity and the human good. 
Journal Committed to Social Change on Race and Ethnicity | Volume 6, Issue 2 | 2020

\section{References}

Astin, A. W. (1993). What matters in college? Four critical years revisited. Jossey-Bass.

Baillie, C., Pawley, A. L., \& Riley, D. (2011). Engineering and social justice in the university and beyond. Purdue University Press.

Beckwith, J., \& Huang, F. (2005). Should we make a fuss? A case for social responsibility in science. Nature Biotechnology, 23(12), 1479-1480.

Bensimon, E. M., \& Bishop, R. (2012). Why "critical"? The need for new ways of knowing. The Review of Higher Education, 36(1), 1-7.

Calabrese Barton, A. (2001). Science education in urban settings: Seeking new ways of praxis through critical ethnography. Journal of Research in Science teaching, 38(8), 899-917.

Calabrese Barton, A., \& Tan, E. (2011). Why democratic science teaching matters. In S. J., Basu, A. Calabrese Barton, \& E. Tan (Eds.), Democratic science teaching: Building the expertise to empower low-income minority youth in science (pp. 115120). Sense Publishers.

Carlone, H. B., \& Johnson, A. (2007). Understanding the science experiences of successful women of color: Science identity as an analytic lens. Journal of Research in Science Teaching, 44(8), 1187-1218.

Chang, M. J., Sharkness, J., Hurtado, S., \& Newman, C. (2014). What matters in college for retaining aspiring scientists and engineers from underrepresented racial groups. Journal of Research in Science Teaching, 51(5), 555-580.

Charleston, L. J. (2012). A qualitative investigation of African Americans' decision to pursue computing science degrees: Implications for cultivating career choice and aspiration. Journal of Diversity in Higher Education, 5(4), 222-243.

Chen, P. D., \& Simpson, P. A. (2015). Does personality matter? Applying Holland's typology to analyze students' self-selection into Science, Technology, Engineering, and Mathematics Majors. Journal of Higher Education, 86(5), 725750.

Feldman, K. A., Ethington, C. A., \& Smart, J. C. (2001). A further investigation of major field and person-environment fit: Sociological versus psychological interpretations of Holland's theory. Journal of Higher Education, 72, 670-698.

Feldman, K. A., Smart, J. C., \& Ethington, C. A. (2008). Using Holland's theory to study patterns of college student success: The impact of major fields on students. In J. C. Smart (Ed.) Higher Education: Handbook of Theory and Research (Vol. 23, pp. 329-380). Springer.

Feldman, K. A., Smart, J. C., \& Ethington, C. A. (2004). What do college students have to lose? Exploring the outcomes of differences in Person-Environment Fits. Journal of Higher Education, 75(5), 528-555.

Feldman, K. A., Smart, J. C., \& Ethington, C. A. (1999). Major field and personenvironment fit: Using Holland's theory to study change and stability of college students. Journal of Higher Education, 70, 642-669.

Frankenstein, M. (1983). Critical mathematics education: An application of Paulo Freire's epistemology. Journal of Education, 165(4), 315-340.

Frankenstein, M. (2012). Beyond math content and process: Proposals for underlying aspects of social justice education. In A. A. Wager, \& D. W. Stinson (Eds.), 
Journal Committed to Social Change on Race and Ethnicity | Volume 6, Issue 2 | 2020

Teaching Mathematics for Social Justice: Conversations with Educators (pp. 4962). National Council of Teachers of Mathematics.

Garibay, J. C. (2015). STEM students' social agency and views on working for social change: Are STEM disciplines developing socially and civically responsible students? Journal of Research in Science Teaching, 52(5), 610-632.

Garibay, J. C. (2018). Beyond traditional measures of STEM success: Long-term predictors of social agency and conducting research for social change. Research in Higher Education, 59(3), 349-381.

Garibay, J. C., \& Vincent, S. (2018). Racially Inclusive Climates Within Degree Programs and Increasing Student of Color Enrollment: An Examination of Environmental/Sustainability Programs. Journal of Diversity in Higher Education. 11(2), 201-220.

Gottfredson, G. D., \& Holland, J. L. (1996). Dictionary of Holland occupational codes ( $3^{\text {rd }}$ ed.). Psychological Assessment Resources.

Gutstein, E. (2006). Reading and writing the world with mathematics: Toward a pedagogy for social justice. Routledge.

Hammonds E. M., \& Herzig, R. M. (2009). The nature of difference: Sciences of race in the United States from Jefferson to Genomics. The MIT Press.

Harding, S. (2006). Science and social inequality: Feminist and postcolonial issues. University of Illinois Press.

Harper, S. R., \& Newman, C. B. (Eds.) (2010). Students of color in STEM. New Directions for Institutional Research, 148. Jossey-Bass.

Higher Education Research Institute [HERI], (2010). Degrees of Success: Bachelor's degree completion rates among initial STEM majors. UCLA Higher Education Research Institute. http://www.heri.ucla.edu/nih/downloads/2010\%20\%20Hurtado,\%20Eagan,\%20Chang\%20-\%20Degrees\%20of\%20Success.pdf

Holland, J. L. (1966). The psychology of vocational choice. Blaisdell.

Holland, J. L. (1973). Making vocational choices: A theory of vocational personalities and work environments. Prentice-Hall.

Holland, J. L. (1985). Making vocational choices: A theory of vocational personalities and work environments ( $2^{\text {nd }}$ ed.). Prentice-Hall.

Holland, J. L. (1997). Making vocational choices: A theory of vocational personalities and work environments ( $3^{\text {rd }}$ ed.). Psychological Assessment Resources.

Huang. Y., \& Healy, C. C. (1997). The relations of Holland-typed majors to students' freshman and senior work values. Research in Higher Education, 38, 455-477.

Johnson, A. C. (2007). Unintended consequences: How science professors discourage women of color. Science Education, 91(5), 805-821.

Jordan, T. (2006). Science and civic engagement: Changing perspectives from Dewey to DotNets. In J. J. Mintzes \& W. H. Leonard (eds.), Handbook of College Science Teaching (pp. 387-394).: National Science teachers Association Press.

Lima, M. (2000). Service-Learning: A unique perspective on engineering education. In E. Tsang (ed.), Projects that matter: Concepts and models for service-learning in engineering (pp. 109-117). AAHE.

Martin, D. B. (2003). Hidden assumptions and unaddressed questions in mathematics for all rhetoric. The Mathematics Education, 13(2), 7-21. 
Journal Committed to Social Change on Race and Ethnicity | Volume 6, Issue 2 | 2020

McGee, E. O. (2020). Interrogating structural racism in STEM higher education. Educational Researcher. Advance online publication. DOI: 10.3102/0013189X20972718

McGee, E., \& Bentley, L. (2017). The Equity Ethic: Black and Latinx College Students Reengineering their STEM Careers toward Justice. American Journal of Education, 124(1), 1-36.

McGee, E. O., White, D. T., Jenkins, A. T., Houston, S., Bentley, L. C., Smith, W. J., \& Robinson, W. H. (2016). Black engineering students' motivation for Ph.D. attainment: Passion plus purpose. Journal for Multicultural Education, 10(2), 167193.

Milem, J. F., \& Umbach, P. D. (2003). Examining the perpetuation hypothesis: The influence of pre-college factors on students' predispositions regarding diversity activities in college. Journal of College Student Development, 45(5), 611-624.

Museus, S. D., Palmer, R. T., Davis, R. J., \& Maramba, D. C. (2011). Racial and ethnic minority students' success in STEM education. ASHE-Higher Education Report Series. Jossey-Bass.

National Academy of Sciences (NAS). (2007). Rising above the gathering storm: Engerginzing and employing America for a brighter economic future. Washington, DC: National Academies Press.

National Science Board (NSB). (2004). An emerging and critical problem of the science and engineering labor force: A companion to science and engineering indicators 2004. Retrieved from www.nsf.gov/statistics/nsb0407/nsb0407.pdf.

National Science Foundation, National Center for Science and Engineering Statistics [NSF]. (2019). Women, Minorities, and Persons with Disabilities in Science and Engineering: 2019. Special Report NSF 19-304.

https://ncses.nsf.gov/pubs/nsf19304/digest

National Science Foundation [NSF], National Center for Science and Engineering Statistics [NCSES]. (2017). Women, minorities, and persons with disabilities in science and engineering: 2017. Special Report NSF 17-310. https://www.nsf.gov/statistics/2017/nsf17310/static/downloads/nsf17310digest.pdf

National Science Foundation [NSF], National Center for Science and Engineering Statistics [NCSES]. (2013). Women, minorities, and persons with disabilities in science and engineering: 2013. Special Report NSF 13-304. http://www.nsf.gov/statistics/wmpd/2013/pdf/nsf13304_digest.pdf

National Science Foundation [NSF]. (2011). Report on Women, Minorities and Persons with Disabilities. National Science Foundation. http://www.nsf.gov/statistics/wmpd/2013/start.cfm

Newman, C. B. (2011). Access and success for African American engineers and computer scientists: A case study of two predominantly white public research universities (Unpublished doctoral dissertation). University of California, Los Angeles.

Nicholls, G. M., Wolfe, H., Besterfield-Sacre, M., Shuman, L. J., \& Larpkiattaworn, S. (2007). A method for identifying variables for predicting STEM enrollment. Journal of Engineering Education, 96(1), 33-44. 
Journal Committed to Social Change on Race and Ethnicity | Volume 6, Issue 2 | 2020

Palmer, R. T., Maramba, D. C., \& Gasman, M. (Eds.) (2012). Fostering success of ethnic and racial minorities in STEM: The role of minority serving institutions. Routledge.

Pike, G. R. (2006a). Students' personality types, intended majors, and college expectations: Further evidence concerning psychological and sociological interpretations of Holland's theory. Research in Higher Education, 47, 801-822.

Pike, G. R. (2006b). Vocational preferences and college expectations: An extension of Holland's principle of self-selection. Research in Higher Education, 47, 591-612.

Porter, S. R., \& Umbach, P. D. (2006). College major choice: An analysis of personenvironment fit. Research in Higher Education, 47(4), 429-449.

President's Council of Advisors on Science and Technology (PCAST). (2012). Engage to Excel: Producing one million additional college graduates with degrees in science, technology, engineering, and mathematics.

www.whitehouse.gov/sites/default/files/microsites/ostp/pcast-engage-to-excel.pdf

Raudenbush, S. W., \& Bryk, A. S. (2002). Hierarchical linear models: Applications and data analysis methods ( $2^{\text {nd }}$ ed.). Sage Publishing.

Reardon, R., \& Bullock, E. (2004). Holland's theory and implications for academic advising and career counseling. NACADA Journal, 24, 111-122.

Rendón, L. I. (2006). Reconceptualizing success for underserved students in higher education. Washington, DC: National Postsecondary Education Cooperative. https://nces.ed.gov/npec/pdf/resp_Rendon.pdf

Rogosa, D., Brandt, D., \& Zimowski, M. (1982). A growth curve approach to the measurement of change. Psychological Bulletin, 92(3), 726-748.

Rosen, D., Holmberg, K., \& Holland, J. L. (1989). The college majors finder. Psychological Assessment Resources.

Sax, L. J. (2000). Citizenship development and the American college student. In T. Ehrlich (ed.), Civic responsibility and higher education (pp. 3-18). Oryx Press.

Semega, J., Kollar, M., Creamer, J., \& Mohanty, A. (2019). Income and poverty in US: 2018, US Census Bureau, Current Population Reports. US Government Printing Office.

Seymour, E., \& Hewitt, N. (1997). Talking about leaving: Why undergraduates leave the sciences. Westview.

Sharkness, J., DeAngelo, L., \& Pryor, J. (2010). CIRP Construct Technical Report. Los Angeles: UCLA Higher Education Research Institute. http://www.heri.ucla.edu/PDFs/constructs/Appendix2009.pdf

Smart, J. C., Feldman, K. A., \& Ethington, C. A. (2000). Academic disciplines: Holland's theory and the study of college students and faculty. Vanderbilt University Press.

Smart, J. C., Feldman, K. A., \& Ethington, C. A. (2006). Holland's theory and patterns of college student success. National Postsecondary Education Cooperative. http://nces.ed.gov/npec/pdf/smart_team_report.pdf

Snijders, T., \& Bosker, R. (1999). Multilevel analysis: An introduction to basic and advanced multilevel modeling. Sage.

Stage, F. K. (2007). Answering critical questions using quantitative data. New Directions for Institutional Research, 133, 5-16. Jossey-Bass.

Tate, W. R. (1995). Returning to the root: A culturally relevant approach to mathematics pedagogy. Theory into Practice, 34(3), 166-173. 
Journal Committed to Social Change on Race and Ethnicity | Volume 6, Issue 2 | 2020

Umbach, P. D., \& Milem, J. F. (2004). Applying Holland's typology to the study of differences in student views about diversity. Research in Higher Education, 45(6), 625-649.

U.S. Department of Education National Center for Education Statistics. (n.d.). Classification of Instructional Programs (CIP 2000). http://nces.ed.gov/pubs2002/cip2000/index.asp.

Van der Leeden, R. (1998). Multilevel analysis of repeated measures data. Quality \& Quantity, 32, 15-29.

Vaz, R. F. (2005). Connecting science and technology education with civic understanding: A model for engagement. Peer Review, 7(2), 13-16.

Zuñiga, X., Williams, E. A., \& Berger, J. B. (2005). Action-oriented democratic outcomes: The impact of student involvement with campus diversity. Journal of College Student Development, 46(6), 660-678. 


\section{Appendix A: List of STEM Majors}

BIOLOGICAL SCIENCES

Biology (general)

Biochemistry/Biophysics

Botany

Marine (Life) Science

Microbiology/Bacteriology

Zoology

Other Biological Science

\section{COMPUTER SCIENCE/TECHNOLOGY}

Computer Science

Health Technology (medical, dental, laboratory)

\section{ENGINEERING}

Aeronautical/Astronautical Engineering

Civil Engineering

Chemical Engineering

Computer Engineering

Electrical or Electric Engineering

Industrial Engineering

Mechanical Engineering

Other Engineering
ENVIRONMENTAL SCIENCES

Environmental Science

Atmospheric Science (incl. Meteorology)

Earth Science

Marine Science (incl. Oceanography)

HEALTH PROFESSIONAL SCIENCES

Medicine/Dentistry/Veterinary Medicine

Nursing

Pharmacy

MATHEMATICS/STATISTICS

Mathematics

Statistics

\section{PHYSICAL SCIENCES}

Astronomy

Chemistry

Physics

Other Physical Science 